\title{
Sobre o lugar da Fenomenologia do Espírito no sistema de filosofia
}

\author{
Prof. Dr. Eduardo Luft (PUCRS)
}

10 de agosto de 2008

\begin{abstract}
Resumo
A filosofia hegeliana não assumiu desde o princípio a figura de uma metafísica crítica. A transição gradual para a defesa de uma ciência capaz de unificar criticidade e sistematicidade pode explicar a posição ambígua ocupada pela Fenomenologia do Espírito no sistema dialético. Primeiramente, ela assumirá função outrora deixada, ainda no período de Iena, a cargo da Lógica: tratar-se-ia de um saber crítico-propedêutico em relação ao sistema de filosofia propriamente dito. Mas a Fenomenologia de 1807 é mais do que mera propedêutica: ela inclui o primeiro passo de justificação do Conceito, o princípio do sistema de filosofia. Sendo assim, por que posteriormente Hegel pensou ser possível deslocar a Fenomenologia, de introdução crítica ao sistema, a parte integrante da Filosofia do Espírito Subjetivo? O presente artigo defende a tese de que a razão para tal deslocamento residiria na defesa, pelo Hegel maduro, do caráter radicalmente autárquico do processo de autojustificação do Conceito desenvolvido na Lógica. Segue-se, então, a exposição e crítica da tese hegeliana da autarquia da Lógica, com a reproblematização da relação entre Fenomenologia do Espírito e Lógica no contexto de uma visão renovada do pensamento dialético. fia

Palavras-chave: Hegel, Fenomenologia do Espírito, Sistema de Filoso-

The Hegelian philosophy did not assume, from the beginning, the role of a critical metaphysics. The gradual transition to a defense of a science that has the potential to integrate critical and systematical thinking can explain the ambiguous position occupied by the Phenomenology of Spirit within the dialectical system. At the beginning, the Phenomenology adopted the function initially reserved to the Logic, at the period of Iena, that means, it was conceived as a critical-propaedeutical knowledge concerning the system of philosophy as a whole. But the Phenomenology of 1807 has to be thought as more than a mere propaedeutic: it has to include the first level of the justification of the concept, the principle of the system of philosophy. If this is the case, why has Hegel subsequently supposed that it was possible to displace the Phenomenology from its original position in the system, from a critical introduction to the Logic to a member of the Philosophy of Subjective Spirit? This paper defends the thesis that the reason of this displacement has to do with the defense, for the mature
\end{abstract}


Hegel, of the radical autarkical character of the process of self-justification of the concept developed in the Logic. The paper also intends to expose and criticize the Hegelian thesis of the autarkical character of the Logic, with a renewed view of the relation between the Phenomenology of Spirit and the Logic in the context of a renewed conception of the dialectical thinking.

Keywords: Hegel, Phenomenology of Spirit, System of Philosophy

\section{Sistematicidade e criticidade: a herança kantiana}

A nova metafísica que emerge do pensamento moderno carrega consigo duas exigências: a filosofia deve preservar-se como saber de totalidade, e ao mesmo tempo radicalizar-se como pensamento crítico.

Que o pensamento filosófico deva visar o todo, deva ser pensamento sistemático, depreende-se das palavras de Kant, centrais para compreender o desdobramento subseqüente de suas idéias no Idealismo Alemão:

"Compreendo por arquitetônica a arte dos sistemas. Sendo a unidade sistemática o que faz de simples conhecimento ciência, ou seja, transforma um mero agregado de conhecimentos em sistema, a arquitetônica é a doutrina do que há de científico em nosso conhecimento em geral" 1 .

Logo adiante, na mesma "Arquitetônica da Razão Pura", lemos: "Entendo por sistema a unidade dos múltiplos conhecimentos sob uma idéia"2.

A orientação pela totalidade é fator constitutivo do ato de pensar. O pensamento, dirá Kant, é "conhecimento através de conceitos"3, e o conceito é uma "consciência que une o múltiplo [da intuição] sob uma representação"4. A busca por unidade é a tarefa do pensamento: ao pensar articulamos unidades cada vez mais abrangentes, em um primeiro momento ainda lastreadas na experiência referidas a objetos -, ao final integradas na unidade última que consuma o processo cognitivo: a totalidade concebida como idéia reguladora.

Em sua pulsão pela totalidade, a filosofia kantiana pouco se distingue da tradição; na verdade, nesse quesito ela pouco se distingue de qualquer saber que se queira filosófico ${ }^{5}$. O que caracteriza esta nova forma de fazer filosofia não é a busca pelo Todo, mas o modo de empreendê-la.

A busca deve ser empreendida, como sabemos desde Descartes, pela radicalização da dúvida: o pensamento sistemático deve ser criticamente estabelecido.

\footnotetext{
${ }^{1} \mathrm{KrV}, \mathrm{B} 860$.

${ }^{2}$ Id. Ibid.

${ }^{3}$ Id. B94.

${ }^{4}$ Id. A103.

${ }^{5} \mathrm{O}$ ceticismo não é uma exceção. Sua recusa pelo Todo implica a generalização do puro Aparecer, a afirmação do Aparecer que aparece apenas para si mesmo, e não para um sujeito dogmaticamente pressuposto. A estrutura reflexiva do puro Aparecer é apenas a própria totalidade rediviva, repensada em outra configuração. Cf. sobre este tópico M. Conche, Orientação filosófica, p.370 e E. Luft, Sobre a coerência do mundo, p.66.
} 
É por isso que, para Kant, se a filosofia emergirá em sua plenitude na forma de um sistema da razão pura, este deve ser precedido por uma Crítica da Razão Pura, um Tratado do Método ${ }^{6}$, cuja função é justamente apresentar-se como a mediação negativa necessária para a renovação da metafísica. Se a história da metafísica é vista por Kant como um campo de batalhas (Kampfplatz) sem fim, a Crítica é o Tribunal que avaliará as diferentes pretensões levantadas pelas diversas filosofias a partir do reconhecimento prévio das estruturas a priori da razão e dos limites do seu uso legítimo.

Note-se, porém, que somente em Hegel, embora tentativamente já em Fi$\operatorname{chte}^{7}$, criticidade e sistematicidade serão elevadas a momentos do núcleo duro do sistema filosófico. Em Descartes, a dúvida é apenas uma fase do processo reflexivo do espírito, que ao final transmudar-se-á na certeza do cogito. Em Kant, a Crítica é apenas uma propedêutica, embora incontornável, do sistema de filosofia propriamente dito: ela é "o ato prévio necessário à promoção de uma metafísica [concebida] como ciência"8. Nesse sentido, pode-se afirmar que na dialética hegeliana vê-se consumada uma das principais pretensões da modernidade: a realização de uma metafísica crítica.

\section{A Fenomenologia do Espírito como saber crítico-propedêutico}

A filosofia hegeliana não assumiu desde o princípio a figura de uma metafísica crítica. A transição gradual para a defesa de uma ciência capaz de unificar criticidade e sistematicidade pode explicar a posição ambígua ocupada pela Fenomenologia do Espírito no sistema dialético ${ }^{9}$.

Em uma das primeiras versões do sistema de filosofia em Iena ${ }^{10}$, Hegel ainda preserva a dualidade kantiana entre uma ciência propedêutico-crítica e o sistema propriamente dito. A Lógica era concebida com um saber crítico cuja função era problematizar o modo de pensar do entendimento. Se a Crítica da Razão Pura lançara a dúvida contra os pilares da metafísica clássica, Hegel pretende que sua Lógica mine os pressupostos dogmáticos ainda implícitos no criticismo

\footnotetext{
${ }^{6} \mathrm{KrV}, \mathrm{BXXII}$.

${ }^{7}$ A Doutrina da Ciência de Fichte contém uma sutil combinação de procedimento regressivocrítico e progressivo-dogmático, embora com ênfase para o último: a criticidade emerge apenas da posição do filósofo que tematiza a estrutura do Eu, procurando reconhecer ainda tentativamente em que ela consiste. Mas o Eu em si mesmo precede, e na verdade funda, a dúvida filosófica. Cf. § 4 da Doutrina da Ciência (WL-1794) e E. Luft, As sementes da dúvida, p.96. ${ }^{8} \mathrm{KrV}, \mathrm{BXXXVI}$

${ }^{9}$ Como afirma Trede, "a concepção hegeliana de crítica filosófica destaca-se pelo fato de ser sistemática - não apenas no sentido de que ela procura dar conta de seu objeto em sua completude, mas sobretudo por ser considerada, via sua explicação completa, momento integrante do desenvolvimento sistemático das determinações de uma razão pensada de modo absoluto. Este é o ponto de vista da Ciência da Lógica de 1812-16 e, expressamente, da Enciclopédia das Ciências Filosóficas de 1817-30. Todavia, Hegel não pensou desse modo desde o início, mas desenvolveu em Iena, desde 1801, a dimensão crítica da filosofia em uma lógica que precede e antecede a metafísica (ou "filosofia") e, em 1806, a formulou em uma Fenomenologia do Espírito considerada como parte específica do sistema, embora ele estivesse consciente desde o início (...) do caráter problemático e provisório de um tal empreendimento" ("Hegels Frühe Logik (1801-1803/04)", 1972, p.127).

${ }^{10}$ Hegel, LM, 1801/02.
} 
kantiano.

A Lógica deveria expor as "formas da finitude [categorias] não empiricamente, mas como resultam da razão, todavia roubadas da razão pelo entendimento e aparecendo apenas em sua finitude"11. Esta afirmação hegeliana leva a crer que o que estava em jogo na virada dialética, ao menos ao tempo de Iena, não era tanto formular uma nova lista de categorias, mas reformular desde a raiz certa interpretação dos conceitos a priori com o intuito de superar a leitura meramente analítica do entendimento. A Lógica exporia as categorias e ao mesmo tempo dissolveria o modo do entendimento de concebê-las, dando lugar ao conhecimento filosófico do absoluto, à verdadeira metafísica. Ela teria, portanto, uma função introdutória em relação ao sistema de filosofia.

Com a gênese da Lógica madura, a dualidade entre pensamento crítico e sistemático é superada em nome de uma ciência concebida ao mesmo tempo como crítica e reconstrução do pensar metafísico ${ }^{12}$. A atividade abstrativa do entendimento, gênese da finitização das categorias, e produtora das contradições daí decorrentes, será concebida agora como momento ${ }^{13}$ do processo de autojustificação negativa do Conceito, e não mais como elemento integrante de uma ciência propedêutica à Nova Metafísica.

Nesse contexto, a função de introdução ao sistema será transferida da Lógica de Iena para a Fenomenologia do Espírito ${ }^{14}$. De fato, a Fenomenologia pode ser considerada uma metacrítica ao criticismo kantiano, uma metaepistemologia ${ }^{15}$ que terá por função dissolver o ceticismo epistemológico de corte transcendental, encaminhar o sujeito pensante ao reconhecimento do caráter incontornável da dimensão ontológica, e conduzi-lo ao âmbito da Lógica, onde um ceticismo de outro corte, metafísico, será exposto e refutado. A metacrítica fenomenológica pode ser entendida como uma radicalização da dúvida, um aprofundamento do diálogo com o ceticismo, cujo alvo prioritário é o dogmatismo ainda presente na Filosofia Transcendental kantiana.

Devemos ter em mente dois dogmas centrais do kantismo: a) a pressuposição da coisa-em-si, a crença de que há um mundo subjetivamente constituído e a nós acessível, distinto da totalidade do incognoscível (realismo dogmático); b) a convicção de que o giro reflexivo fornece ao sujeito um ponto seguro, um fundamento inconcusso a partir do qual poderíamos julgar, de uma perspectiva exterior e neutra, as disputas filosóficas, ou seja, o Tribunal da Razão Pura (idealismo dogmático). Se a Crítica kantiana parte da tese de que os conflitos filosóficos que permeiam a tradição ocidental devem ser resolvidos mediante o apelo ao Tribunal da Razão Pura, a Fenomenologia do Espírito descrê frontalmente da possibilidade de julgar tais conflitos pelo recurso a qualquer quadro

\footnotetext{
${ }^{11}$ Id., p.272.

$12 \mathrm{M}$. Theunisse, Sein und Schein.

${ }^{13}$ Trata-se da dimensão "dialética ou negativo-racional" do lógico (cf. Hegel, Enz, v.8, §79).

14"Somente quando passou a conceber a Fenomenologia do Espírito como introdução à Lógica, ao mesmo tempo em que afirmava a Lógica como fundamento desta Fenomenologia, pôde Hegel iniciar a Lógica com uma definição do absoluto, sem precisar recorrer, como era o caso em sua primeira exposição do sistema, a uma intuição (intelectual) da idéia do absoluto em oposição a seu conceito" (M. Baum, Die Entstehung der Hegelschen Dialektik, p.162).

${ }^{15}$ Cf. E. Luft, "A Fenomenologia como metaepistemologia"
} 
referencial fixo.

Esse ponto de vista vem a aprofundar uma conviç̧ão antiga de Hegel: a crítica externa é insustentável em Filosofia ${ }^{16}$. Sendo assim, o que nos resta é enfrentar o oponente a partir de sua própria perspectiva, e miná-la de dentro, na confiança de que por trás das disputas filosóficas repousa uma "unidade nos princípios"17. É importante destacar que a crítica interna é o único caminho legítimo a se tomar não apenas quando duas filosofias rivais estão em disputa, mas também quando a filosofia busca defender seus supostos perante o senso comum; esta tese é decisiva para Fenomenologia e algo diferente em relação à posição anterior assumida por Hegel na recensão a Schulze ${ }^{18}$. O idealismo objetivo de cunho hegeliano precisará ser justificado também perante o senso comum, cujo realismo ingênuo terá de ser superado via crítica imanente.

A Fenomenologia inicia justamente investigando de dentro a posição do realista ingênuo (consciência), para superá-la em um idealismo subjetivo (autoconsciência), por sua vez radicalizado e resolvido no exato momento em que o sujeito reconhece como sua a essência do mundo, ou seja, com a emergência do idealismo objetivo (razão). Nesse sentido, a Fenomenologia não é apenas introdução, mas introdução e justificação crítica do conceito de ciência e, portanto, do próprio sistema de filosofia frente posições antagônicas: "O conceito de ciência pura e sua dedução está pressuposto no presente tratado, enquanto a Fenomenologia do Espírito não é mais do que sua dedução"19.

\section{Lógica sem Fenomenologia: a autarquia da sistematici- dade}

Como pode a Lógica, fundante de um saber absoluto, conter fora de si a justificação primeira de seu conceito? A justificação fenomenológica do conceito de ciência residiria fora da Lógica ou, mais ainda, fora do sistema de filosofia, como crê Fulda ${ }^{20}$ ?

Acredito, todavia, que Hegel tenha levado a tal ponto sua crença na autonomia radical do lógico frente a qualquer pressuposto a ele externo, que a revisão posterior do lugar da Fenomenologia no sistema dialético, com sua realocação no âmbito da Filosofia do Espírito Subjetivo, na Enciclopédia, se vê justificada - ao menos aos olhos de Hegel. Assim, o fechamento da Lógica sobre si mesma, sua autojustificação radical, extensiva à totalidade ${ }^{21}$ do sistema dialético que

\footnotetext{
${ }^{16}$ Cf. E. Luft, Para uma crítica interna ao sistema de Hegel, p.13ss.

${ }^{17}$ Hegel, Skep., 1801, p.216.

${ }^{18}$ A crítica interna torna-se viável justamente sob aquela suposição, também ela questionável e só legitimável pela mediação da dúvida, da existência de uma unidade dos princípios que perpassa toda filosofia; ocorre que, conforme Hegel afirma na recensão a Schulze, "algo diverso ocorre nas disputas entre filosofia e não filosofia" (Id., p.216).

${ }^{19}$ WL, v.5, p.43.

20"Como introdução, a Fenomenologia não é um momento integrante do sistema (de filosofia)" (H. F. Fulda, Das Problem einer Einleitung in Hegels Wissenschaft der Logik, p.110).

${ }^{21} \mathrm{E}$ não a apenas algumas partes dele, como parece afirmar a tese de Puntel sobre a co-originariedade de noologia, lógica e fenomenologia (Darstellung, Methode und Struktur, p.237)
} 
dela emerge, dispensaria qualquer fundamentação primeira do Conceito perante posições filosóficas rivais e o próprio senso comum, tornando supérfluo o apelo a uma introdução que se quer ao mesmo tempo científica e externa ao sistema de filosofia, e dispensáveis todas as ambigüidades que brotam desta polêmica tese de Fulda, tão bem apontadas por Puntel ${ }^{22}$.

É verdade que a Lógica pressupõe, no sentido acima mencionado, a Fenomenologia do Espírito. Mas ela também carrega consigo outros pressupostos: por exemplo, a presença das categorias aí depositadas na linguagem ${ }^{23}$, repositório da longa e conflitada tradição filosófica ocidental, assim como a decisão do filósofo de pensar o próprio pensamento ${ }^{24}$. Estes vínculos podem ser compreendidos como a conseqüência direta, e quase banal, da própria estrutura circular do sistema: a Lógica está, por assim dizer, no ápice de todo devir histórico do pensamento ocidental. Nesse sentido, toda Filosofia do Real a precede. Mas esta condicionalidade genética não significa necessariamente dependência lógica ou de validade. Hegel acreditava ter encontrado na dialética justamente o método capaz de oferecer uma saída original para o problema do começo da Lógica, ou seja, para a necessidade de partir de pressupostos ou condicionamentos ao elaborar e justificar a arquitetônica do sistema de filosofia.

O assim-chamado "problema do começo" é a contrapartida hegeliana do trilema cético da fundamentação ${ }^{25}$, segundo o qual todo processo de justificação do conhecimento termina refém de pelo menos um dos três impasses: a) parada dogmática; b) regresso ao infinito na cadeia de provas; c) circularidade viciosa. Utilizando terminologia típica da epistemologia contemporânea de corte analítico, poderíamos dizer: no confronto com o trilema, Hegel recusa as alternativas do fundacionismo e do infinitismo ${ }^{26}$, em nome de um coerentismo ${ }^{27}$ sui generis. Digo sui generis porque o coerentismo hegeliano está permeado pelo que denomino uma teleologia do incondicionado, como veremos no que segue, o que o torna um coerentismo restrito, ainda não inteiramente liberado de pressupostos fundacionistas.

No capítulo "Com o que deve ser feito o começo da ciência", que inaugura a Doutrina do Ser, Hegel afirma enfaticamente que o começo "não deve pressupor nada"28. Na verdade, não se trata de partir de um ponto radicalmente vazio de pressupostos, o que é impossível; trata-se, sim, de considerar o começo não fundamento do sistema de filosofia, mas o ponto de partida de uma autocrítica da razão. O pensamento dialético investiga o Todo, eleva cada uma das categorias por ele tematizadas a conceitos com pretensão de totalidade, de autarquia semântica, e descobre paulatinamente que cada uma das categorias tratadas pressupõe outra categoria a ela oposta e é incapaz de mostrar-se com

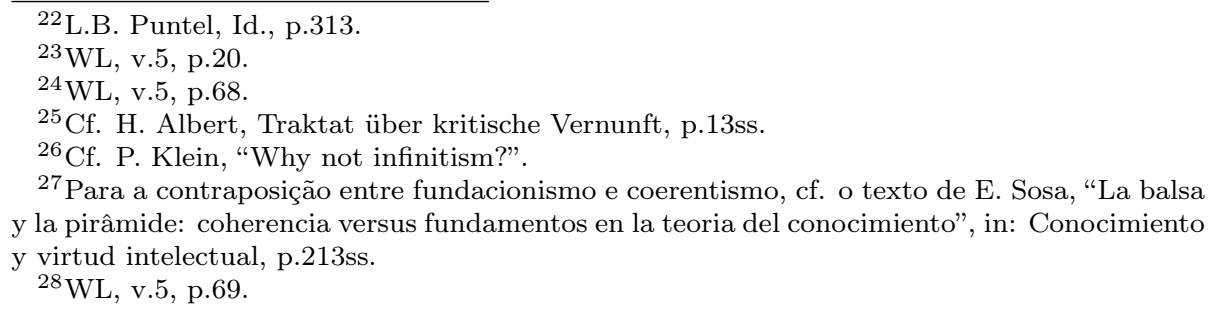


validade incondicionada. O processo segue até encontrarmos a única categoria não condicionada por nenhuma outra a ela externa, a categoria que estrutura o sistema categorial como um todo, a "idéia" 29

Se a cada passo a emergência da contradição e a exigência de sua superação revelam a criticidade inerente ao pensamento, a superação da contradição pela conciliação de opostos na síntese constitui a dimensão sistemática que, para Hegel, manifesta-se em um processo de justificação mediante síntese a priori. O progredir dialético seguiria, desse modo, um desenvolvimento necessário que culminaria na autofundamentação última do saber. Trata-se de um movimento orientado por um fim absoluto, e é nesse sentido que o Conceito hegeliano configura-se no contexto de uma teleologia do incondicionado.

Como prescreve a teleologia circular ${ }^{30}$ do Conceito, todos os pressupostos tomados ao início do processo dialético serão repostos e justificados na imanência da Lógica. A Lógica pode pressupor a justificação fenomenológica do conceito de ciência, assim como a decisão do filósofo de tematizar o próprio pensamento, ou ainda a história pregressa da filosofia que permitiu explicitar as categorias fundamentais do pensamento. Todos estes pressupostos podem ser aceitos como inevitáveis, desde que a Lógica seja capaz de liberar-se radicalmente de tais condicionamentos, típicos da situação de início da atividade de pensamento, e originantes do "problema do começo", no interior do próprio movimento de autofundamentação última do Conceito.

Ao executar sua própria fundamentação absoluta, liberando-se de todos os condicionamentos a ela externos, a Lógica mostra-se muito mais do que momento do sistema: ela é a ciência que, em sua autarquia, constitui a estrutura mesma do sistema de filosofia. Autarquia que a própria Lógica deve ser capaz de provar. O idealismo objetivo hegeliano supõe a contraposição entre a esfera lógica e a esfera real, e pensa a primeira como autônoma e não contaminada pelas contingências da segunda. Só por isso Hegel pode afirmar: "O mesmo desenvolvimento do pensamento que se apresenta na história da filosofia é exposto na própria filosofia, mas livre da exterioridade histórica, no puro elemento do pensar" ${ }^{\prime 31}$.

Sendo assim, faz sentido pensar que a realocação da Fenomenologia de primeira parte do sistema, ou sua introdução, para momento da Filosofia do Espírito Subjetivo, é uma conseqüência natural do projeto de uma radical autarquia do lógico.

\footnotetext{
${ }^{29}$ Para os detalhes desta reconstrução do modelo de prova hegeliano, cf. E. Luft, As sementes da dúvida, p.154ss.

${ }^{30}$ Sobre o caráter algo paradoxal deste conceito, cf. M. Z. A. da Silva: "Quando se critica o fim da história em Hegel, o que se tem em mente é o esquema finalista, e não o circular. Portanto, seria correto supor que haveria, na filosofia hegeliana, um confronto insolúvel entre o círculo e o avanço da reta?" (A teleologia especulativa de Hegel, p.151). A meu ver, o conceito deixa de ser problemático uma vez abandonado o postulado de uma teleologia fixista, ou do incondicionado, em prol de uma teleologia dinâmica (cf. E. Luft, Sobre a coerência do mundo, p.5-6). Na teleologia do incondicionado de cunho hegeliano o movimento para o fim tende a se dissolver em um processo circular redundante.

${ }^{31}$ Enz, v.8, $\$ 14$.
} 


\section{Dialética como saber crítico-sistemático:}

o círculo produtivo entre Lógica e Fenomenologia

Cabe, contudo, perguntar se este saber radicalmente autárquico ainda é um saber crítico. Acredito, com Gadamer, que a dialética hegeliana tenha apenas transmudado o problema do começo em um enigma do fim ${ }^{32}$.

Como vimos, a dialética hegeliana é caracterizada não apenas pela presença da negatividade no processo lógico, mas pela conceituação deste enquanto orientado para um fim absoluto. Por meio da teleologia do incondicionado, o desenvolvimento lógico se plenifica na fundamentação última do sistema das categorias, o transcurso fenomenológico resulta em um saber absoluto e, por sua vez, o processo histórico-civilizacional desemboca em um conceito absolutizado de Estado.

Ocorre que o dinamismo dialético pressupõe o possível surgimento de novas incoerências, a serem sanadas por novos desdobramentos lógicos. Pelo contrário, a plenificação do Conceito em um sistema categorial autofundamentado de modo último implica a supressão da possibilidade de emergência de novas determinações categoriais (e possíveis novas incoerências) e, com isso, a supressão do dinamismo dialético. Orientado para a realização de um fim absoluto, o processo dialético condena-se a desembocar na sua própria aniquilação ${ }^{33}$. A Lógica conquista sua autarquia às custas da dialética e do pensamento crítico.

Mas o que ocorreria se eliminássemos da dialética justamente este elemento, ou seja, a teleologia do incondicionado que, adaptada às peculiaridades do pensamento hegeliano, vincula o filósofo alemão mais a Aristóteles que a Platão ${ }^{34}$ ? Não posso desenvolver este tema aqui em toda a sua amplitude ${ }^{35}$. Quero apenas explicitar a sua relevância para uma possível releitura da Fenomenologia do Espírito, e de sua relação com a Lógica.

Já vimos que a Fenomenologia tem por princípio a tese de que a crítica externa é inviável em filosofia. Pois, na falta de um quadro referencial fixo, de um fundamento inconcusso a partir do qual pudéssemos resolver de saída qualquer disputa entre sistemas filosóficos rivais, não nos resta outra alternativa senão entrar em diálogo franco com o oponente, partindo da investigação crítica de seus pressupostos. O antifundacionismo implícito nesta tese hegeliana fora mitigado, todavia, pelo recurso à teleologia do incondicionado, à idéia de que todo diálogo poderia ser visto como um momento no devir necessário do conhecimento em direção à sua plenificação em um saber absoluto. Agora é preciso radicalizá-lo.

A dúvida assim radicalizada suspende qualquer adesão imediata a essa ou àquela filosofia. É no todo do diálogo intersubjetivo, em que os quadros referenciais antagônicos são postos em questão, que o conflito pode ser sanado (coerentismo). Mesmo a tese universalíssima de que deve haver uma unidade

\footnotetext{
32"O problema do começo é, ocorra onde ocorrer, em verdade o problema do fim" (H.G.Gadamer, Wahrheit und Methode, p.476).

${ }^{33}$ Cf. E. Luft, As sementes da dúvida, p.178ss.

${ }^{34}$ Cf. M. S. Sorondo, Aristóteles y Hegel.

${ }^{35}$ Para os desdobramentos desta tese de uma necessária renovação do pensamento dialético e suas implicações para a elaboração de um novo projeto de sistema de filosofia, cf. E. Luft, Sobre a coerência do mundo.
} 
subjacente a todas as disputas filosóficas para que o próprio diálogo entre os oponentes seja possível permanece como hipótese que só pode ser provada indiretamente - por via negativa -, restando, portanto, destituída de fundamentação última ${ }^{36}$

Não havendo mais uma orientação a um fim último do processo dialógico, o jogo dos conflitos e sua contínua superação, com emergência de novos conflitos, e assim sucessivamente, permanece inconcluso; o processo dialético se estende, portanto, potencialmente ao infinito (infinitismo). O coerentismo dialético deve ser compreendido, portanto, como uma forma de coerentismo infinitista.

Eliminada da dialética a teleologia do incondicionado, como supor que a Fenomenologia possa desembocar em um saber absoluto e, portanto, em uma Lógica de corte hegeliano? Ou, pior, como supor que a Lógica possa ser capaz de promover a fundamentação última do sistema categorial, liberando-se radicalmente de todos os seus pressupostos? Pensada em suas últimas conseqüências, a dialética conduz ao reconhecimento de que a tensão entre a posição epistêmica e a posição lógico-ontológica é insanável. Pretendemos dizer o Todo (posição lógico-ontológica), mas o fazemos sempre tentativamente (posição epistêmica).

De um lado, a Fenomenologia pressupõe a Lógica. Isso ocorre pela incoerência do ceticismo subjetivista. Se o dualismo coisa-em-si/fenômeno é insustentável, precisamos reconhecer que a totalidade do dizível é co-extensiva à totalidade do mundo, mesmo aceitando o caráter problemático do discurso sobre a totalidade. Temos, portanto, de tornar explícita a lógica (metafísica) implícita em nosso discurso crítico. Por outro lado, a impossibilidade de fundamentação última do discurso sobre a totalidade nos conduz sempre de volta ao diálogo com as variadas formas de ceticismo: a Lógica pressupõe a Fenomenologia.

O projeto contemporâneo de construção de uma Filosofia Sistemática deve abranger e conciliar ambas as pretensões: tal filosofia deve ser capaz, por um lado, de revelar as pressuposições lógico-ontológicas do discurso cético, virando a postura epistêmica ao avesso em uma metaepistemologia que convida à investigação metafísica; por outro lado, ela deve propiciar ao metafísico a consciência de que tudo o que temos é uma ontologia falibilista, e convidá-lo ao caminho inverso e ao diálogo renovado com as ciências particulares, passando pelo crivo do saber empírico e, como horizonte último, pela mediação corrosiva da dúvida cética.

A circularidade entre Lógica e Fenomenologia só não é viciosa porque os elementos que a compõem estão expostos a contínuas, potencialmente infinitas, alterações e aperfeiçoamentos. Destaque-se o caráter potencial da infinitude aqui pressuposta. Já Poincaré alertara que o apelo a uma noção de infinitude atual está na gênese do círculo vicioso e das antinomias da nova lógica: "É óbvio também que em sua opinião [de Poincaré], o círculo vicioso que deu origem aos paradoxos da teoria dos conjuntos era de um gênero especial e relacionado com a tentativa de tratar um conjunto infinito como uma totalidade acabada"37.

Se o círculo Lógica/Fenomenologia fosse concebido como uma forma de sa-

${ }^{36}$ Cf. E. Luft, "Fundamentação última é viável?".

${ }^{37}$ W. Kneale/M;Kneale, O Desenvolvimento da Lógica, p.662. 
ber absoluto, uma totalidade acabada de determinações, como ocorrera com a Lógica hegeliana, cairíamos em uma circularidade viciosa. Pelo contrário, acredito que o infinitismo potencial inerente ao coerentismo dialético aqui defendido transforma um movimento de pressuposição mútua supostamente redundante e, portanto, vicioso - em um processo produtivo de autojustificação, uma boa circularidade ${ }^{38}$.

\section{Referências}

[1] Albert, H. Traktat über kritische Vernunft. 5.ed. Tübingen: Mohr, 1991.

[2] Baum, M. Die Entstehung der Hegelschen Dialektik. Bonn: Bouvier, 1986.

[3] Conche, M. Orientação filosófica. São Paulo: Martins Fontes, 2000.

[4] Fichte, J.G. Grundlage der gesammten Wissenschaftslehre [Wl-1794]. In: Fichtes Werke. Ed. I.H.Fichte. Berlin: de Gruyter, 1971, v.1.

[5] Fulda, H. F. Das Problem einer Einleitung in Hegels Wissenschaft der Logik. 2.ed. Frankfurt am Main: Vittorio Klostermann, 1975.

[6] Gadamer, H.-G. Wahrheit und Methode. Grundzüge einer philosophischen Hermeneutik. 6.ed. Tübingen: Mohr, 1990.ermeHer

[7] Hegel, G.W.F. Logica et metaphysica [LM]. In: Gesammelte Werke. Ed. Deutschen Forschungsgemeinschaft. Hamburg: Meiner, 1968ss, v.5.

[8] _ _ _ _. Wissenschaft der Logik [WL]. In: Georg Wilhelm Friedrich Hegel: Werke. 2.ed. Frankfurt am Main, 1990, v.5-6.

[9] ___ _ . Enzyklopädie der philosophischen Wissenschaften [Enz]. In: Georg Wilhelm Friedrich Hegel: Werke. 2.ed. Frankfurt am Main, 1989, v.8-10.

\footnotetext{
${ }^{38}$ Poder-se-ia objetar, contudo, que a pressuposição recíproca entre Lógica e Fenomenologia ocorre apenas do ponto de vista epistêmico, ou seja, a condicionalidade do pensar metafísico diria respeito apenas à perspectiva de quem pensa a totalidade no contexto de um saber finito. Ocorre que o coerentismo infinitista não envolve apenas uma nova forma de conceber a epistemologia dialética; pelo contrário, trata-se de uma tese a respeito da dialética como tal e, portanto, incidente também e principalmente na ontologia. Em termos hegelianos: a Lógica perde sua autonomia não apenas no sentido epistêmico, mas também no sentido ontológico: o princípio do sistema de filosofia não se encerra em uma esfera ideal, para ao depois (no sentido lógico, e não temporal) se manifestar no real sem perder sua absolutidade; o princípio é o cerne do real, o que nos conduz do Idealismo Objetivo ao Ideal-Realismo, para utilizar terminologia do jovem Schelling, embora com outra intenção (cf. Schelling, Über den wahren Begriff der Naturphilosophie und die richtige Art ihre Probleme aufzulösen, 1801, p.21). O absoluto não é incondicionado, mas autocondicionado, contendo intrinsecamente um momento ineliminável de contingência e historicidade. Mas estas são teses que nos conduzem além do almejado no presente ensaio.
} 
[10] _ _ . Verhältnis des Skeptizismus zur Philosophie. Darstellung seiner verschiedenen Modifikationen und Vergleichung des neuesten mit dem alten [Skep.]. In: Georg Wilhelm Friedrich Hegel: Werke. 2.ed. Frankfurt am Main, 1990, v.2.

[11] Kant, I. Kritik der reinen Vernunft [KrV]. 3.ed. Hamburg: Meiner, 1990.

[12] Klein, P. D. "Why not infinitism?". In: R. Cobb-Stevens (ed.). Epistemology: Proceedings of the Twentieth World Congress in Philosophy. Bowling Green: Bowling Green State University, 2000, v.5, p.199-108.

[13] Kneale, W./Kneale, M. O desenvolvimento da Lógica. 3.ed. Lisboa: Fundação Calouste Gulbenkian, 1991.

[14] Luft, E. "A Fenomenologia como metaepistemologia", Revista Eletrônica Estudos Hegelianos, v.3, n.4, 2006.

[15] _ _ _. Sobre a coerência do mundo. Rio de Janeiro: Civilização Brasileira, 2005.

[16] _ _ _ . As sementes da dúvida. Investigação crítica dos fundamentos da filosofia hegeliana. São Paulo: Mandarim, 2001.

[17] _____. "Fundamentação última é viável?". In: Cirne-Lima, C./Almeida, C. Nós e o absoluto. Festschrift em homenagem a Manfredo Araújo de Oliveira. São Paulo: Loyola, 2001.

[18] _ _ _ . Para uma crítica interna ao sistema de Hegel. Porto Alegre: Edipucrs, 1995.

[19] Puntel, L.B. Darstellung, Methode und Struktur. Untersuchungen zur Einheit der systematischen Philosophie G.W.F. Hegels. 2.ed. Bonn: Bouvier, 1981.

[20] Schelling, F.W.J. Über den wahren Begriff der Naturphilosophie und die richtige Art ihre Probleme aufzulösen. In: Ausgewählte Schriften. 2.ed. Frankfurt am Main: Suhrkamp, 1995, v.2.

[21] Silva, M. Z. A. da. A teleologia especulativa de Hegel. Vida lógica e vida do espírito. Tese de Doutorado. Campinas: Unicamp, 2006.

[22] Sorondo, M. S. Aristóteles y Hegel. Buenos Aires/Roma: Universidades Pontifícias, 1987.

[23] Sosa, E. Conocimiento y virtud intelectual. México: Fondo de Cultura Econômica, 1992.

[24] Theunissen, M. Sein und Schein. Die kritische Funktion der Hegelschen Logik. 2.ed. Frankfurt am Main: Suhrkamp, 1994.

[25] Trede, J. H. "Hegels Frühe Logik (1801-1803/04). Versuch einer systematischen Rekonstruktion", Hegel-Studien, Bonn, v.7, p.123-168, 1972. 